\title{
COMMENTARY
}

\section{Caring for young carers in Canada}

\author{
Nicholas Chadi MD, Vivian Stamatopoulos MA
}

Cite as: CMAJ 2017 July 17;189:E925-6. doi: 10.1503/cmaj.170145

D ata from Statistics Canada show that 1.18 million young carers aged 15 to 24 provide some level of unpaid caregiving for a family member with long-term illness, disability, cognitive impairment or health problems related to aging. ${ }^{1}$ Of this number, $10 \%$ spend 20 hours or more providing care each week, helping with activities of daily living, such as dressing, laundry and bathing, and/or more complex tasks, such as organizing medical appointments or financial planning. There are young carers in every community in Canada, but they are often invisible to their peers, teachers and health care providers. Caregiving can be a positive experience, but when unsupported, young carers are at high risk of social, academic, and mental and physical health difficulties. ${ }^{2}$

The aging of the Canadian population, combined with an overburdened public health care system, is creating a high demand for family caregivers. The movement of women into the workplace in the past decades has made it more challenging for families to care for their elders at home and has led to an increased reliance on younger caregivers. ${ }^{3}$ In the context of limited resources in health care, supporting young carers is a strategic investment in the future health and well-being of a large group of Canadian youth.

The number of young carers in Canada is increasing. The three waves of Canadian census data that included questions on unpaid care showed a $13.5 \%$ increase in the number of youth aged 15 to 24 who provided care between 1996 and 2006. ${ }^{1}$ Similar to Australian and United Kingdom data, young girls in Canada provide most unpaid caregiving and, in line with the Australian data, there is a growing feminization of this care as these youth age. ${ }^{1}$ Currently, only three programs provide targeted support for Canadian young carers (two in Ontario and one in British Columbia). Services offered through these programs include support groups, respite care, skill-building groups, and summer leadership camps for young carers. Funding for all three of these programs is precarious and relies mostly on grants and philanthropy. ${ }^{3}$

Lack of support for young carers is an important global problem, but countries like the UK, Australia and the United States have taken meaningful steps to meet the needs of young carers. ${ }^{4,5}$ In the UK, young carers have legal rights as "Carers" under the Care Act, which affords them access to more than 350 dedicated young carer programs and "direct payments" in lieu of services. ${ }^{6}$ Programs provide a range of information, respite, educa-

\section{KEY POINTS}

- Young carers are younger than 25 and provide substantial care to family members with illness or disability.

- There are more than 185000 young carers in Canada aged 15 to 24 who provide 15 or more hours of weekly unpaid caregiving to people with long-term illness, disability or problems related to aging.

- When unsupported, young carers are at high risk for social, academic, and mental and physical health difficulties.

- Programs and legislation in the UK, Australia and some parts of the US have led to improved supports for young carers.

- By recognizing the needs of young carers and advocating for an increase in the support services available to them, physicians can play a key role in promoting the health and well-being of young carers.

tion and counselling-based services to children and youth up to the age of 25. In England, the Children and Families Act (2014) recognizes that young people who care for persons with cognitive impairments, mental illness or substance abuse disorder may also be at risk for violent assault and sexually inappropriate behaviour, and accounts for such concerns by mandating a formal "needs assessment" for each formally recognized young carer and their particular caregiving situation. ${ }^{6}$

In Canada, a tiny minority of young carers has access to direct caregiver support services; in the UK, 1 in 14 young carers accesses such supports. ${ }^{3}$ Accumulating research offers evidence that formal support for young carers has positive impacts on mood and anxiety symptoms, as well as on functioning at school or in the workplace. ${ }^{7}$

Although Australian young carers do not share the same breadth of rights and entitlements as young carers in the UK, they have partial legal rights in select jurisdictions and many have access to educational and social service programming. After research showed Australian young carers were less likely than their peers to be studying or employed full time, the federal Young Carer Bursary Programme was launched in 2015 to increase their opportunities to remain in school. ${ }^{5}$

In 2003, the US Administration on Aging funded the first national survey of "youth caregivers," which opened the way for research on the impacts of caregiving in youth. ${ }^{8}$ However, despite 
the documentation of more than 1.4 million child caregivers between the ages of 8 and 18 years, dedicated young carer programming is limited mainly to Florida. ${ }^{8}$ The remaining states provide varying assistance only to those caregivers aged 18 and older.

In the US, support for young carers emerged from the interest and advocacy work of nurses ${ }^{9}$ and pediatricians. ${ }^{10}$ Physicians can help to identify caregiving youth. Physicians should be aware that young carers may show symptoms of exhaustion, confusion, anger and depression, and that their development and health may become compromised, creating an additional burden on the health and social services. ${ }^{10}$ Physicians can advocate for increasing the funding and capacity of community organizations that provide services for young carers. As it stands, funding limitations for the nonprofit and community sector severely affect the breadth and scope of Canadian young carer programs. ${ }^{3}$ In Canada, we need legal instruments and policies to acknowledge the importance of young carers and actively support their health and well-being. Existing federal caregiver supports should be expanded beyond their current tax creditbased system so they benefit young carers and not only working adult caregivers. The current lack of support for young carers in Canada results in a failure to live up to international obligations to promote and protect the rights and well-being of young people. ${ }^{11}$

There are young carers in classrooms, medical practices and communities across Canada. Many young carers are proud of the care they provide and view it as a positive experience. However, risks emerge when the caregiving begins to interfere with normal child and adolescent development. A first step for physician advocacy could be as simple as asking young people, "Do you provide care or support for a family member or loved one, either in or outside your home?", or writing a short letter to a school teacher or employer to inform them that a youth is a young carer who requires special accommodations owing to caring responsibilities.

\section{References}

1. Stamatopoulos V. One million and counting: the hidden army of young carers in Canada. J Youth Stud 2015;18:809-22.

2. Charles G, Marshall S, Stainton T. Demographics profiles and initial results from the British Columbia young carers study. Relational Child and Youth Care Practice 2010;23:64-7.

3. Stamatopoulos V. Supporting young carers: a qualitative review of young carer services in Canada. Int J Adolesc Youth 2015;21:178-94.

4. Becker S. Global perspectives on children's unpaid caregiving in the family: research and policy on "young carers" in the UK, Australia and sub-Saharan Africa. Glob Soc Policy 2007;7:23-50.

5. Cass B, Smyth C, Hill T, et al. Young carers in Australia: understanding the advantages and disadvantages of their care giving. Social Policy Research Paper No. 38. Canberra (Australia): Australian Government - Department of Families, Housing, Community Services and Indigenous Affairs; 2009.

6. Children and Families Act 2014: Chapter 6. London (UK): The Stationery Office; 2014.

7. Clay D, Connors C, Day N, et al. The lives of young carers in England: qualitative report to DfE. Darlington (UK): Department for Education; 2016.

8. Kavanaugh MS, Stamatopoulos V, Cohen D, et al. Unaknowledged caregivers: a scoping review of research on caregiving youth in the United States. Adolescent Res Rev 2016;1:29.

9. Brandt $P$, Weinert $C$. Children's mental health in families experiencing multiple sclerosis. J Fam Nurs 1998;4:41-64.

10. Barber M, Siskowski C. Youth caregivers: unrecognized providers of care. Pediatrics 2008;121:873-4.

11. Bednar V, Chadi N, DeCourcey M, et al. Who cares about young carers? Raising awareness for an invisible population. Action Canada Task Force Report. Ottawa: Action Canada; 2013.

\section{Competing interests: None declared.}

This article has been peer reviewed.

Affiliations: Division of Adolescent Medicine, The Hospital for Sick Children (Chadi), Toronto, Ont.; Faculty of Social Sciences and Humanities (Stamatopoulos), University of Ontario Institute of Technology, Oshawa, Ont.

Contributors: Nicholas Chadi and Vivian Stamatopoulos drafted the initial manuscript, revised the manuscript and approved the final manuscript as submitted.

Correspondence to: Nicholas Chadi, nicholas.chadi@umontreal.ca 